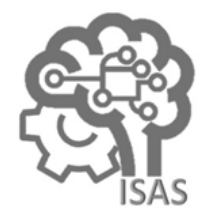

JOURNAL OF APPLIED CIVIL ENGINEERING AND INFRASTRUCTURE TECHNOLOGY (JACEIT)

Vol. 2 No. 1 (2021) $6-11$

ISSN Media Elektronik: 2723-5378

\title{
Pengaruh Pemanfaatan Plastik Polyethylene Terephalate Pada Campuran Laston Lapis Pengikat
}

\author{
Ifani Mita'ul Habibah ${ }^{1}$, Mirza Gulam Rifqi ${ }^{2}$, dan Dadang Dwi Pranowo \\ 1,2,3 Jurusan Teknik Sipil, Politeknik Negeri Banyuwangi \\ 1ifanimitaul@gmail.com, ${ }^{2}$ mirza@poliwangi.ac.id, ${ }^{3}$ dadangdp@poliwangi.ac.id
}

\begin{abstract}
Plastic Polyethylene Terephthalate (PET) waste can be utilized as an added ingredient in a mixture of fastening concrete asphalt (Laston AC-BC). The purpose of this research is to know the influence of the utilization of PET plastics (Polyethylene Terephthalate) on the layer of concrete asphalt binder (Laston AC-BC) using the Marshall method by referring to the design guidelines and implementation of the heat-paved mixture using plastic waste 2019 and the general specification of Highways 2018.

This research is done with the addition of PET worms on the asphalt mixture using a dry process. PET levels added in the asphalt mixture are $4 \%, 4.5 \%$, and $5 \%$ of the weight of the asphalt.

After the Marshall testing, the results of PET additions to the Laston AC-BC mixture can improve stability. The highest stability value is the addition of PET 5\%. The stability value due to PET addition is greater than without the addition of PET. The best PET replenishment rate for asphalt mixture is 5\% because, in addition to high stability value, other Marshall parameters such as Flow, VIM, VMA, VFB, and MQ also qualify for the design guidelines and implementation of the hot paved mixture using plastic waste 2019. Value of Optimum asphalt content (KAO) obtained at a $6 \%$ asphalt rate with the addition of PET $5 \%$.
\end{abstract}

Keywords: AC-BC, PET, Dry process, Marshall parameters, General specification of Bina Marga 2018.

\begin{abstract}
Abstrak
Limbah plastik Polyethylene Terephthalate (PET) dapat dimanfaatkan sebagai bahan tambah pada campuran aspal beton lapis pengikat (Laston AC-BC). Tujuan penelitian ini adalah untuk mengetahui pengaruh pemanfaatan plastik PET (Polyethylene Terephthalate) pada aspal beton lapis pengikat (Laston AC-BC) menggunakan metode Marshall dengan mengacu pada Pedoman Perancangan dan Pelaksanaan Campuran Beraspal Panas Menggunakan Limbah Plastik 2019 dan Spesifikasi Umum Bina Marga 2018. Penelitian ini dilakukan dengan penambahan cacahan PET pada campuran aspal menggunakan cara kering (dry process). Kadar PET yang ditambahkan dalam campuran aspal yaitu 4\%, 4,5\%, dan 5\% dari berat aspal. Setelah dilakukan pengujian Marshall, hasil dari penambahan PET pada campuran Laston AC-BC dapat meningkatkan stabilitas. Nilai stabilitas tertinggi yaitu pada penambahan PET 5\%. Nilai stabilitas akibat penambahan PET lebih besar dibandingkan tanpa penambahan PET. Kadar penambahan PET terbaik untuk campuran aspal yaitu 5\% karena selain nilai stabilitas yang tinggi, parameter Marshall yang lain seperti Flow, VIM, VMA, VFB, dan MQ juga memenuhi syarat Pedoman Perancangan dan Pelaksanaan Campuran Beraspal Panas Menggunakan Limbah Plastik 2019. Nilai Kadar Aspal Optimum (KAO) yang diperoleh pada kadar aspal 6\% dengan penambahan PET 5\%.
\end{abstract}

Kata kunci: AC-BC, PET, Dry process, parameter Marshall, Spesifikasi Umum Bina Marga 2018.

Diterima Redaksi : 01-07-2021 | Selesai Revisi : 25-07-2021 | Diterbitkan Online : 02-08-2021

\section{Pendahuluan}

Lapis aspal beton (Laston) terdiri dari tiga macam campuran yaitu laston sebagai lapis aus (AC-WC), laston sebagai lapis pengikat (AC-BC), dan laston sebagai lapis pondasi (AC-Base). Material penyusun pada lapis aspal beton terdiri atas agregat kasar, agregat halus, bahan pengisi (filler), dan bahan aspal itu sendiri dengan perbandingan tertentu [14].
Bahan aspal dalam campuran merupakan bahan yang berfungsi sebagai pengikat antar agregat. Sedangkan agregat merupakan komponen yang cukup dominan dan berfungsi sebagai bahan penyusun campuran lapis aspal beton. Namun agregat juga memiliki pori-pori atau rongga yang tidak pasti sehingga dapat menurunkan daya ikat antar agregat akibat aspal masuk ke dalam pori tersebut. Untuk mengatasi masalah tersebut maka ditambahkam limbah plastik yang 
berfungsi untuk menyelimuti pori pada agregat agar antara agregat dan aspal melekat sempurna [2].

PET (Polyethylene Terephthalate) merupakan jenis plastik yang biasa digunakan untuk kemasan makanan atau botol minuman dan yang hanya bisa digunakan dalam sekali penggunaan sehingga plastik ini banyak terbuang.

Menurut [2] pada penelitiannya yang berjudul Pengaruh Pemanfaatan PET pada Laston Lapis Pengikat Terhadap Parameter Marshall, kadar PET yang memenuhi persyaratan Marshall yaitu pada kadar $2 \%$. Namun berdasarkan [1], nilai kadar plastik yang disyaratkan antara $4 \%-6 \%$.

Oleh karena itu, dilakukan penelitian aspal plastik PET dengan kadar $0 \% ; 4 \% ; 4,5 \% ; 5 \%$ dengan harapan agar jumlah sampah plastik PET khususnya bekas botol minuman dapat berkurang dan dapat diketahui pengaruh pemanfaatan plastik PET (Polyethylen Terephthalate) pada Laston Lapis Pengikat (AC-BC).

\section{Metode Penelitian}

Penelitian ini dilakukan di Laboratorium Uji Bahan Jalan Teknik Sipil Politeknik Negeri Banyuwangi. Penelitian yang dilakukan yaitu dengan penambahan plastik jenis Polyethylene Terephalate dan menggunakan aspal penetrasi 60/70 yang mengacu pada [14].

Langkah-langkah pelaksanaan penelitian menggunakan Metode Marshall yang dilakukan pada penelitian ini adalah sebagai berikut:
2.1 Studi pustaka
2.2 Persiapan alat dan bahan
2.3 Pengujian material
2.4 Rancangan campuran
2.5 Penentuan kadar aspal optimum (KAO)
2.6 Pembuatan benda uji
2.7 Pengujian marshall
2.8 Analisis dan pembahasan
2.9 Kesimpulan dan saran

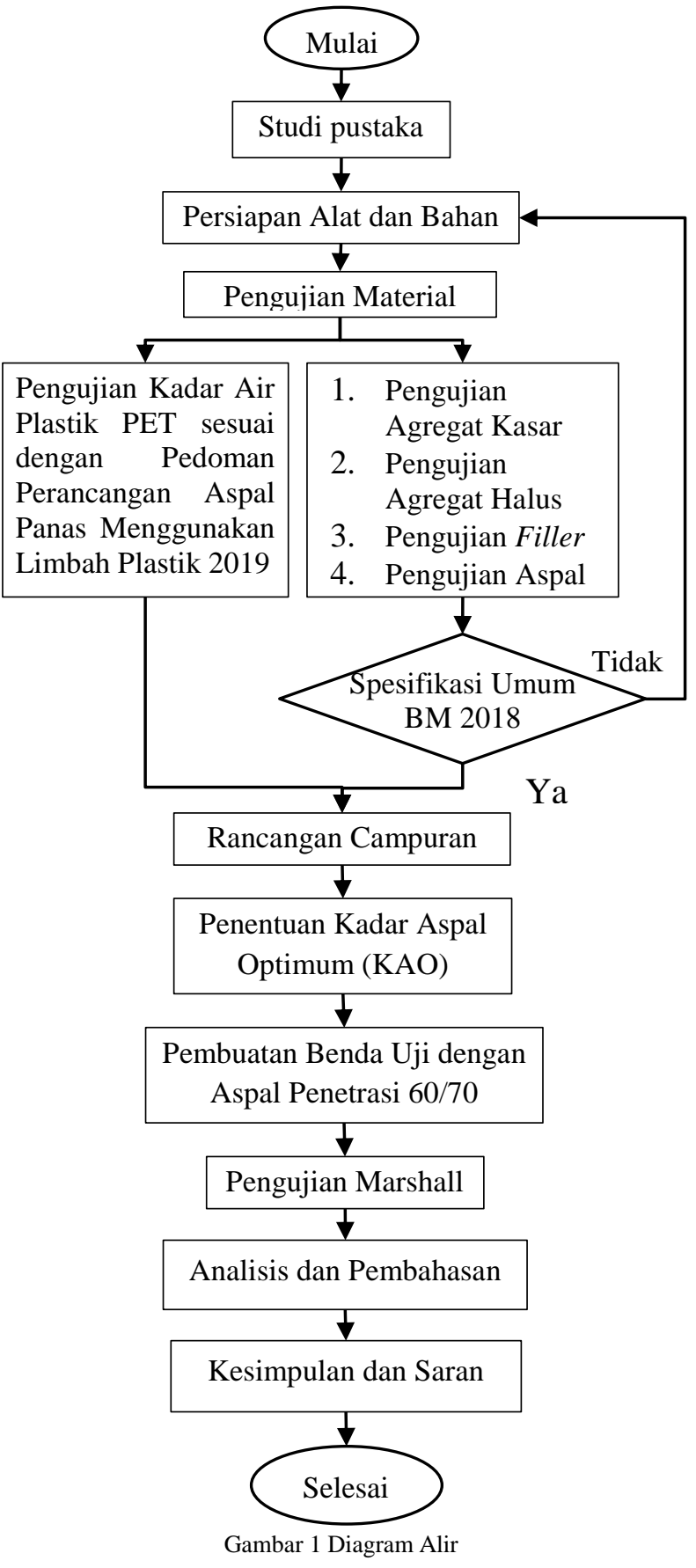

3. Hasil dan Pembahasan

3.1 Hasil Pengujian Agregat dan Aspal

Pengujian agregat yang dilakukan pada penelitian Proyek Akhir ini diantaranya pengujian berat jenis agregat, pengujian lolos saringan No. 200, pengujian impact, pengujian Los Angeles, pengujian analisis saringan, dan pengujian berat jenis filler. Sedangkan pengujian aspal yang dilakukan yaitu pengujian titik nyala, pengujian titik lembek, pengujian daktilitas, pengujian berat jenis aspal. Dari semua pengujian yang telah dilakukan telah memenuhi [14]. 


\subsection{Stabilitas}

Stabilitas dalam perkerasan jalan sangat diperlukan untuk menahan beban lalu lintas tanpa menimbulkan perubahan yang tetap, seperti bergelombang (bleeding) dan retak, Hasil rekapitulasi nilai stabilitas dapat dilihat pada Tabel 1

\begin{tabular}{|c|c|c|c|c|}
\hline \multirow{2}{*}{$\begin{array}{l}\text { Macam } \\
\text { Campuran }\end{array}$} & \multicolumn{4}{|c|}{ Stabilitas } \\
\hline & PET 0\% & PET 4\% & $\begin{array}{l}\mathrm{PET} \\
4.5 \% \\
\end{array}$ & PET 5\% \\
\hline $4.5 \%$ & 1381.93 & 1589.41 & 1682.03 & 1745.01 \\
\hline $5.0 \%$ & 1370.82 & 1498.78 & 1633.87 & 1782.06 \\
\hline $5.5 \%$ & 1293.01 & 1293.01 & 1307.83 & 1363.41 \\
\hline $6.0 \%$ & 1267.08 & 1322.65 & 1322.65 & 1389.34 \\
\hline $6.5 \%$ & 1263.37 & 1298.01 & 1341.18 & 1378.23 \\
\hline Spesifikasi & MIN. 900 & $\begin{array}{l}\text { MIN. } \\
900\end{array}$ & MIN. 900 & MIN. 900 \\
\hline
\end{tabular}

Hasil pengujian stabilitas yang terdapat pada Tabel 1 selanjutnya data tersebut dipaparkan dalam bentuk grafik yang dapat dilihat pada Gambar 2.

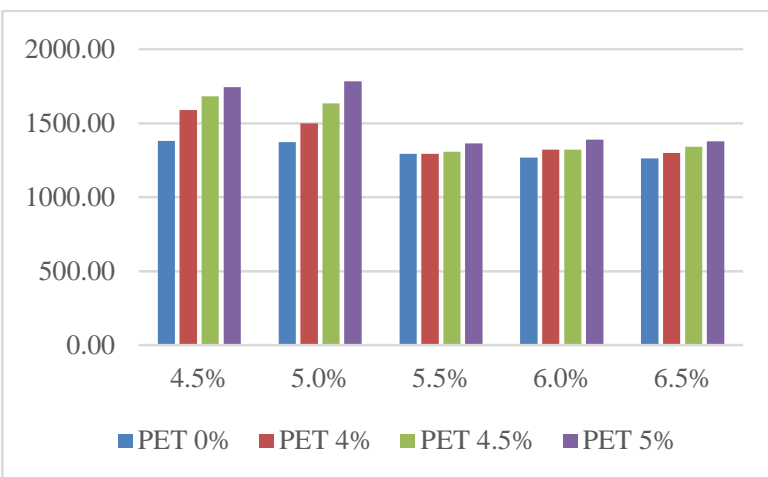

Gambar 2. Grafik Rekapitulasi Nilai Stabilitas
Tabel 2 Rekapitulasi Nilai Flow

\begin{tabular}{ccccc}
\hline $\begin{array}{c}\text { Macam } \\
\text { Campuran }\end{array}$ & PET 0\% & PET 4\% & $\begin{array}{l}\text { PET } \\
4.5 \%\end{array}$ & PET 5\% \\
\hline $4.5 \%$ & 3.11 & 3.23 & 3.84 & 4.59 \\
\hline $5.0 \%$ & 2.78 & 3.70 & 3.72 & 4.01 \\
\hline $5.5 \%$ & 3.07 & 3.42 & 3.97 & 3.99 \\
\hline $6.0 \%$ & 3.79 & 3.82 & 3.83 & 3.99 \\
\hline $6.5 \%$ & 3.85 & 3.86 & 4.04 & 4.81 \\
\hline Spesifikasi & $2-4$ & $2-4$ & $2-4$ & $2-4$ \\
\hline
\end{tabular}

Hasil pengujian flow yang terdapat pada Tabel 2 selanjutnya data tersebut dipaparkan dalam bentuk grafik yang dapat dilihat pada Gambar 3.

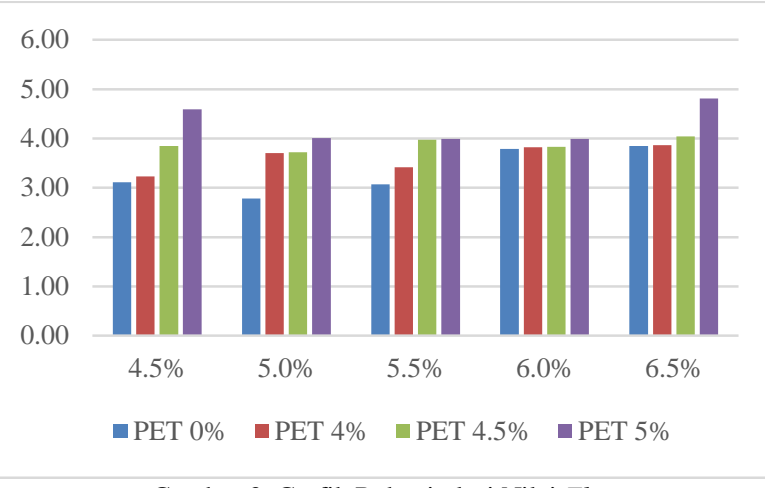

Gambar 3. Grafik Rekapitulasi Nilai Flow

Berdasarkan Gambar 3 dapat dilihat bahwa dengan adanya penambahan PET nilai flow mengalami peningkatan mulai kadar aspal 4,5\% sampai dengan kadar aspal 6,5\%. Nilai flow yang berada diantara nilai yang disyaratkan yaitu pada kadar PET 0\% sampai dengan kadar PET 4,5\%, sedangkan pada PET 5,5\% nilai flow melebihi nilai maksimum yang sudah Dari Gambar 2 terlihat bentuk grafik semakin ditetapkan. Suatu campuran aspal yang memiliki nilai meningkat seiring dengan adanya penambahan PET flow rendah akan cenderung kaku dan mudah retak, yang menyebabkan meningkatnya nilai stabilitas sedangkan nilai flow tinggi mengindikasikan bahwa campuran aspal. Hal tersebut menunjukkan adanya campuran bersifat plastis sehingga menyebabkan peningkatan daya ikat aspal dan agregat yang bleeding pada perkerasan jalan.

diharapkan mampu mengurangi kerusakan jalan seperti pelepasan butiran, pengelupasan, dan kelembaban.

\subsection{Flow}

\subsection{Rongga Dalam Campuran (VIM)}

Rongga dalam campuran merupakan volume udara total yang berada diantara partikel agregat yang Flow pada suatu campuran aspal menunjukkan terselimuti aspal dalam suatu campuran yang telah kelenturan campuran tersebut yang nilainya melalui proses pemadatan dan dinyatakan dalam persen dipengaruhi oleh besarnya kadar rongga yang ada volume bulk. Hasil rekapitulasi nilai rongga dalam dalam campuran. Semakin banyak rongga yang campuran (VIM) dapat dilihat pada Tabel 3 terbentuk maka akan menimbulkan rongga-rongga yang nantinya akan terisi oleh udara karena tidak terisis oleh aspal atau filler, sehingga menyebabkan benda uji mudah retak. Adapun nilai hasil rekapitulasi flow dapat dilihat pada Tabel 2 . 


\begin{tabular}{ccccc}
\hline \multicolumn{5}{c}{ Tabel 3 Rekapitulasi Nilai Rongga dalam Campuran } \\
\hline $\begin{array}{c}\text { Macam } \\
\text { Campuran }\end{array}$ & \multicolumn{5}{c}{ Rongga dalam Campuran (VIM) } \\
\hline $4.5 \%$ & PET 0\% & PET 4\% & PET 4.5\% & PET 5\% \\
\hline $5.0 \%$ & 9.10 & 8.57 & 8.52 & 7.95 \\
\hline $5.5 \%$ & 4.91 & 7.49 & 6.96 & 5.59 \\
\hline $6.0 \%$ & 4.94 & 4.94 & 4.72 & 4.16 \\
\hline $6.5 \%$ & 5.75 & 4.85 & 4.83 & 4.75 \\
\hline Spesifikasi & $3-5$ & $3-5$ & $3-5$ & $3-5$ \\
\hline
\end{tabular}

Hasil pengujian rongga dalam campuran (VIM) yang terdapat pada Tabel 3 selanjutnya data tersebut dipaparkan dalam bentuk grafik yang dapat dilihat pada Gambar 4.

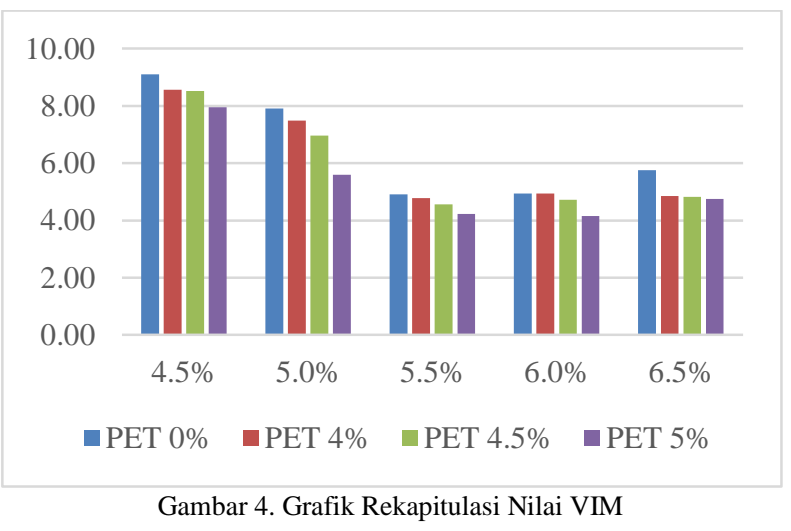

Berdasarkan Gambar 4 terlihat bahwa nilai VIM mengalami penurunan akibat penambahan PET hal tersebut menunjukkan bahwa dalam campuran aspal rongganya semakin kecil. Hal tersebut menunjukkan dengan penambahan PET dalam campuran aspal akan meningkatkan daya ikat yang lebih kuat antara agregat dan aspal sehingga akan menambah umur perkerasan jalan.

\begin{tabular}{ccccc}
\hline \multirow{2}{*}{$\begin{array}{c}\text { Macam } \\
\text { Campuran }\end{array}$} & \multicolumn{5}{c}{ Rongga dalam Agregat (VMA) } \\
\hline $6.0 \%$ & 16.66 & 16.65 & 16.47 & 15.97 \\
\hline $6.5 \%$ & 18.53 & 17.75 & 17.73 & 17.66 \\
\hline Spesifikasi & $>14$ & $>14$ & $>14$ & $>14$ \\
\hline
\end{tabular}

Hasil pengujian rongga dalam agregat (VMA) yang terdapat pada Tabel 4 selanjutnya data tersebut dipaparkan dalam bentuk grafik yang dapat dilihat pada Gambar 5.

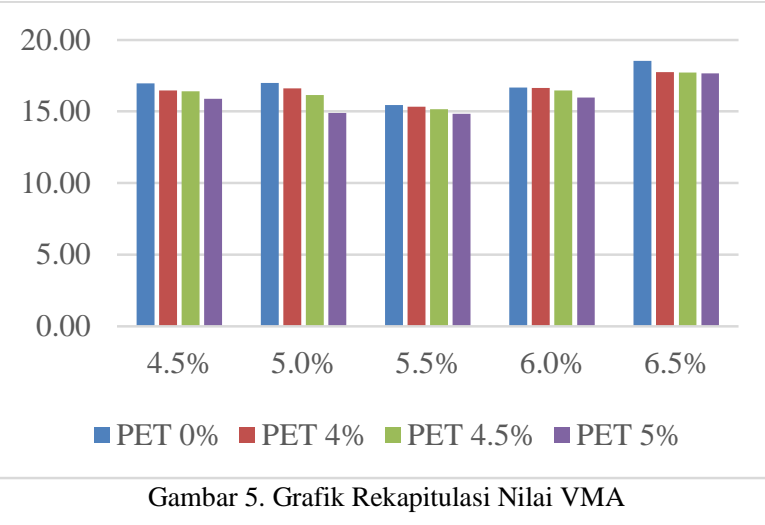

Berdasarkan Gambar 5 dapat dilihat bahwa disetiap penambahan kadar plastik, VMA mengalami penurunan yang artinya rongga didalam agregat semakin kecil akibat penambahan PET. Pada umumnya nilai VMA akan berbanding lurus dengan nilai VIM.

3.6 Rongga Terisi Aspal (VFB)

Rongga teris aspal meruapak persentase rongga yang terisi aspal pada campuran setelah mengalami proses pemadatan. Nilai $V F B$ dipengaruhi oleh jumlah dan temperatur pemadatan, gradasi dan kadar aspal. Hasil rekapitulasi nilai rongga terisi aspal dapat dilihat pada Tabel 5

\subsection{Rongga Dalam Agregat (VMA)}

Rongga dalam agregat merupakan rongga yang terdapat diantara butiran agregat dalamsuatu campuran aspal yang sudah mengalami proses pemadatan dan aspal efektif yang dinyatakan dalam presentase volume total campuran. Hasil rekapitulasi nilai rongga dalam agregat (VMA) dapat dilihat pada Tabel 4

\begin{tabular}{ccccc}
\multicolumn{5}{c}{ Tabel 4 Rekapitulasi Nilai Rongga dalam Agregat } \\
\hline $\begin{array}{c}\text { Macam } \\
\text { Campuran }\end{array}$ & \multicolumn{5}{c}{ Rongga dalam Agregat (VMA) } \\
\hline $4.5 \%$ & 16.95 & 16.47 & 16.42 & 15.90 \\
\hline $5.0 \%$ & 16.99 & 16.61 & 16.14 & 14.91 \\
\hline $5.5 \%$ & 15.46 & 15.34 & 15.15 & 14.84 \\
\hline
\end{tabular}

Tabel 5 Rekapitulasi Nilai Rongga Terisi Aspal (VFB)

\begin{tabular}{ccccc}
\hline Macam & \multicolumn{5}{c}{ Rongga Terisi Aspal (VFB) } \\
Campuran & $\begin{array}{c}\text { PET } \\
0 \%\end{array}$ & $\begin{array}{c}\text { PET } \\
4 \%\end{array}$ & $\begin{array}{c}\text { PET } \\
4.5 \%\end{array}$ & PET 5\% \\
\hline $4.5 \%$ & 46.32 & 48.13 & 48.17 & 50.09 \\
\hline $5.0 \%$ & 53.48 & 55.39 & 57.55 & 63.60 \\
\hline $5.5 \%$ & 68.26 & 68.87 & 70.08 & 71.99 \\
\hline $6.0 \%$ & 70.43 & 70.50 & 71.39 & 73.98 \\
\hline $6.5 \%$ & 69.02 & 72.72 & 72.78 & 73.11 \\
\hline Spesifikasi & MIN 65 & MIN & MIN 65 & MIN 65 \\
\hline
\end{tabular}


Hasil pengujian rongga terisi aspal $(V F B)$ yang terdapat pada Tabel 5 selanjutnya data tersebut dipaparkan dalam bentuk grafik yang dapat dilihat pada Gambar 6 .

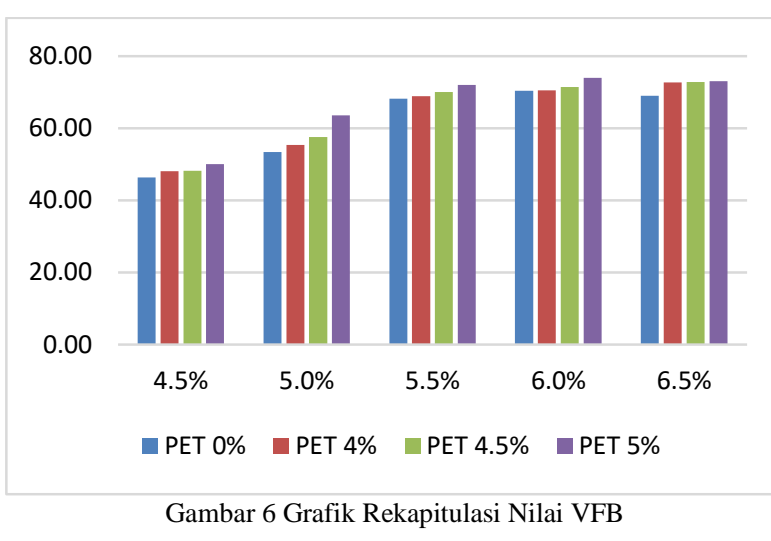

Berdasarkan Gambar 6 terlihat bahwa seiring dengan flow. pertambahan PET nilai $V F B$ semakin meningkat yang artinya rongga yang terisi aspal semakin banyak sehingga kekedapan campuran terhadar air dan udara Kadar Aspal Optimum (KAO) merupakan nilai tengah juga akan semakin tinggi. Namun nilai $V F B$ yang dari rentang adar aspal yang menggambarkan hubungan terlalu tinggi juga kurang baik dikarenakan akan antara kadar aspal dengan nilai dari setiap parameter menyebabkan mudahnya terjadi bleeding sebab rongga karakteristik Marshall yang ememnuhi sifat-sifat yang ada dalam campuran terlalu kecil sehingga campuran sesuai dengan ketentuan yang disyaratkan. menyebabkan aspal naik ke permukaan.

\subsection{Marshall Quotient (MQ)}

Tujuan ditentukannya KAO yaitu untuk mengetahui kadar aspal yang terbaik dan efektif pada campuran lapis aspal beton (Laston). KAO diperoleh dari Marshall Quotient merupakan perbandingan antara hubungan antara parameter pengujian dan kadar aspal stabilitas dan flow yang menunjukkan indeks yang membentuk suatu grafik. Hasil pengujian kelenturan suatu campuran dengan satuan $\mathrm{kg} / \mathrm{mm}$. Nilai Marshall dari campuran aspal dengan penambahan $M Q$ juga menyatakan tingkat kelenturan suatu PET 0\%; 4\%; 4,5\%; 5\% kemudian dihubungkan campuran. Semakin besar nilai $M Q$ menunjukkan dengan diagram yang dapat dilihat pada Gambar 8.

bahwa campuran tersebut kurang baik kerena akan semakin getas. Hasil dari rekapitulasi nilai $M Q$ dapat dilihat pada Tabel 6

\begin{tabular}{ccccc}
\multicolumn{5}{c}{ Tabel 6 Rekapitulasi Nilai MQ } \\
\hline $\begin{array}{c}\text { Macam } \\
\text { Campuran }\end{array}$ & PET 0\% & PET 4\% & PET 4.5\% & PET 5\% \\
\hline $4.5 \%$ & 416.2 & 454.7 & 521.4 & 699.9 \\
\hline $5.0 \%$ & 368.3 & 440.9 & 466.5 & 527.9 \\
\hline $5.5 \%$ & 326.4 & 327.9 & 391.7 & 444.0 \\
\hline $6.0 \%$ & 289.2 & 316.8 & 349.5 & 352.6 \\
\hline $6.5 \%$ & 278.9 & 322.0 & 328.4 & 358.2 \\
\hline & $>250$ & $>250$ & $>250$ & $>250$ \\
\hline 5
\end{tabular}
Hasil pengujian Marshall Quotient (MQ) yang terdapat
pada Tabel 6 selanjutnya data tersebut dipaparkan dalam bentuk grafik yang dapat dilihat pada Gambar 7 .

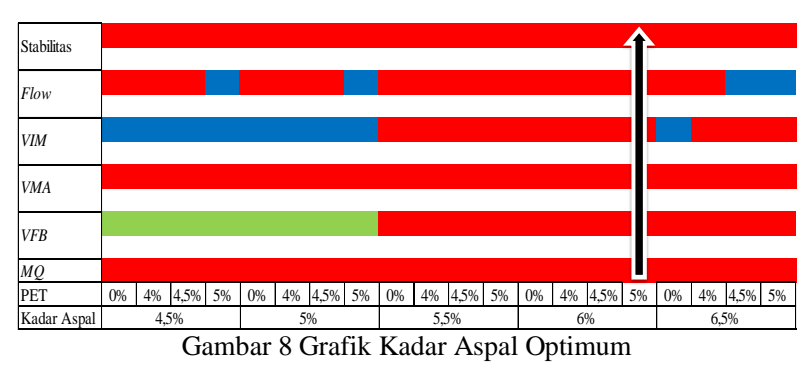

Keterangan:

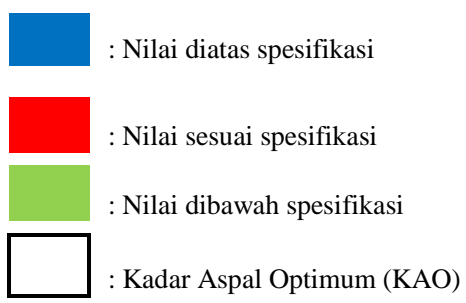

Berdasarkan Gambar 8 menunjukkan hubungan antara parameter Marshall dengan kadar aspal pada penggunaan PET diperoleh kadar aspal optimum yaitu 6\% dengan kadar PET 5\%. Dari hasil tersebut maka dapat diketahui bahwa kadar PET 5\% masih dapat digunakan sebagai tambahan campuran Laston ( $A C$ $B C$ ) dengan kadar aspal 6\%. Pemakaian kadar aspal dibawah dan diatas KAO masih diperbolehkan. Untuk 
diatas KAO kadar PET yang dapat digunakan hanya $4 \%$, sedangkan dibawah KAO kadar PET yang dapat digunakan yaitu anatara rentang $4 \%$ sampai dengan $5 \%$ dengan kadar aspal 5,5\%. Pada kadar aspal 6,5\% yang bisa digunakan hanya kadar PET $4 \%$ dikarenakan terdapat nilai flow yang melebihi nilau maksimum yang disyaratkan pada [1].

\section{Kesimpulan}

Berdasarkan penelitian yang telah dilakukan pada campuran Laston AC-BC dengan penambahan Polyethylene Terephthalate (PET) didapatkan hasil sebagai berikut:

1. Penambahan PET berpengaruh terhadap nilai stabilitas, flow, rongga dalam campuran (VIM), rongga dalam agregat (VMA). Nilai stabilitas dan flow mengalami peningkatan pada setiap penambahan PET. Nilai (VIM) dan (VMA) pada setiap penambahan PET mengalami penururan, hal tersebut menunjukkan bahwa rongga pada campuran aspal semakin kecil akibat terselimutinya pori-pori pada agregat dengan PET sehingga dengan penambahan PET dapat meningkatkan daya ikat yang lebih kuat dan campuran bersifat kedap. Dari hasil penelitian yang telah dilakukan ada beberapa hal yang dapat disarankan untuk dilanjutkan dengan mengombinasikan beberapa jenis plastik dengan komposisi tertentu dalam satu campuran yang sama.

2. Penambahan Polyethylene Terephthalate (PET) sebagai bahan tambah pada campuran Laston AC$\mathrm{BC}$ didapatkan hasil nilai Kadar Aspal Optimum (KAO) pada kadar aspal 6\% dengan kadar PET 5\% dengan nilai stabilitas $1389.34 \mathrm{~kg}$, flow $3,99 \mathrm{~mm}$, rongga dalam campuran (VIM) 4,16\%, rongga dalam agregat $(V M A) 15,97 \%$, rongga terisi aspal (VFB) 73,98\%, dan Marshall Qoutient (MQ) 352,6 $\mathrm{kg} / \mathrm{mm}$ yang sudah memenuhi spesifikasi pada Pedoman Perancangan dan Pelaksanaan Campuran Beraspal Panas Menggunakan Limbah Plastik 2019.

\section{Ucapan Terimakasih}

Terimakasih kepada Politeknik Negeri Banyuwangi khususnya Program Studi Teknik Sipil atas fasilitas yang telah diberikan dan PT. Argotuhu Banyuwangi yang telah memberikan agregat untuk penelitian ini.

\section{Daftar Rujukan}

[1] Pedoman Bahan Konstruksi Bangunan dan Rekayasa Sipil. 2019. Perancangan dan Pelaksanaan Campuran Beraspal
Panas Menggunakan Limbah Plastik. Jakarta: JDIH Kementerian PUPR.

2] Prameswari, P. A., Pratomo, P., \& Harianto, D. 2016. Pengaruh Pemanfaatan PET pada Laston Lapis Pengikat Terhadap Parameter Marshall. JRSSD, 294-305.

[3] SNI 03-4426-1997. 1997. Metode Pengujian Ketahanan Agregat dengan Alat Tumbuk. Jakarta: Pusran Balitbang PU.

[4] SNI 03-6723-2002. 2002. Spesifikasi Bahan Pengisi Untuk Campuran Beraspal. Jakarta: Badan Standardisasi Nasional.

[5] SNI 06-2441-2011. 2011. Pengujian Berat Jenis Aspal Padat. Jakarta: Badab Standardisasi Nasional.

[6] SNI 1969:2016. 2016. Cara Uji Berat Jenis dan Penyerapan Air Agregat Kasar. Jakarta: Badan Standarisasi Nasional.

SNI 1970:2016. 2016. Cara Uji Berat Jenis dan Penyerapan Air Agregat Halus. Jakarta: Badan Standarisasi Nasional.

[8] SNI 2417:2008. 2008. Cara Uji Keausan Agregat Dengan Mesin Abrasi Los Angeles. Jakarta: Badan Standarisasi Nasional.

[9] SNI 2432:2011. 2011. Cara Uji Daktilitas Aspal. Jakarta: Bdan Standarisasi Nasional.

[10] SNI 2433:2011. 2011. Cara Uji Titik Nyala dan Ttitik Bakar Aspal Dengan Alat Cleveland Open Cup. Jakarta: Badan Standarisasi Nasional.

[11] SNI 2434:2011. 2011. Cara Uji Titik Lembek Aspal Dengan Alat Cincin dan Bola (ring and ball). Jakarta: Badan Standarisasi Nasional.

[12] SNI ASTM C117:2012. 2012. Metode Uji Bahan Yang Lebih Halus dari Saringan 75 um (No. 200) dalam Agregat Mineral dengan Pencucian. Jakarta: Badan Standardisasi Nasional.

[13] SNI ASTM C136:2012. 2012. Metode Uji Untuk Analisis Saringan Agregat Halus dan Agregat Kasar. Jakarta: Badan Standarisasi Nasional.

[14] Spesifikasi Umum Bina Marga. 2018. Divisi 6 Perkerasan Aspal. Surabaya: DPU Bina Marga. 